\title{
A RELAÇÃO ENTRE TEXTO E IMAGEM EM CUMBE: UMA ANÁLISE DA TRADUÇÃO DO CONTO SUMIDOURO
}

\author{
The Relation Between Text And Image In Cumbe: Analyzing The \\ Translation Of The Short-Story Sumidouro
}

\author{
Carolina KOSSOSKI \\ Universidade de Brasília \\ carolinak.traducao@gmail.com \\ Júlio César MONTEIRO \\ Universidade de Brasília \\ cesarj1@gmail.com \\ Alessandra HARDEN \\ Universidade de Brasília \\ oliveira.ales@gmail.com
}

RESUMO: Apesar de publicações relativamente recentes (VENUTTI, 2008; KAINDL, 1999), a modalidade de tradução de quadrinhos ainda figura uma posição desvalorizada e até mesmo esquecida dentro da área de Estudos da Tradução. Com base nesse panorama, o presente artigo tem como objetivo tecer uma breve discussão acerca da tradução de HQs e a influência que a justaposição entre texto e imagem infligem no processo tradutório. Para tanto, foi escolhido para análise o romance gráfico Cumbe, de Marcelo D'Salete, e a versão para a língua inglesa do conto Sumidouro. A obra, que foi traduzida e publicada por uma editora norte-americana em 2017, é composta por quatro contos cujos enredos transmitem histórias de negros escravizados durante o Ciclo do Açúcar no Brasil. Tais contos, por sua vez, apresentam uma linguagem verbal e visual próprias, muitas vezes com palavras de origem Banto e explicação de termos e imagens em um glossário ao final do livro. Dessa maneira, foi selecionado o conto Sumidouro e, comparando e contrastando as versões original (brasileira) e traduzida (norte-americana), foram encontradas algumas adaptações próprias à tradução de quadrinhos, as quais envolveram modificações na mensagem verbal e visual. PALAVRAS-CHAVE: Tradução; Quadrinho; Texto; Imagem.

\footnotetext{
ABSTRACT: In spite of fairly recent publications (VENUTTI, 2008; KAINDL, 1999), the translation of comics still holds an unappreciated position and is often forgotten within the Translation Studies. Based on this perspective, this study aims at discussing the translation of co-
} 
mics and how the juxtaposition between text and image influence the translation practice. Therefore, we chose the graphic novel Cumbe, by Marcelo D'Salete, and the English version of its short story, Sumidouro. The book, which was translated and later published by an American publishing house in 2017, is made of four short stories whose plots transit over African enslaved characters during the Ciclo de Açucar in Brazil. These short stories have their own verbal and visual languages, which many times encompass words of Banto origin, as well as explanations of terms and images present in a glossary by the end of the book. In this way, we selected the short story Sumidouro and, by comparing and contrasting the original version (Brazilian one) to its translated version (American one), we have found some aspects related to the translation of comics, which involve alterations in both verbal and visual messages. KEYWORDS: Translation; Comics; Text; Image.

\section{INTRODUÇÃO}

Quando pensamos em Literatura, quase que imediatamente lembramos de livros que fizeram parte da nossa vida, que em algum momento nos ensinaram algo, produziram diferentes emoções e efeitos, ou até mesmo permitiram uma aproximação, ainda que simbólica, entre a vida e a arte. $\mathrm{O}$ ato de narrar histórias, portanto, é inerente ao ser humano, seja através de palavras, seja por meio de elementos imagéticos. Afinal, registros em paredes de cavernas, entalhes em colunas romanas, manuscritos de civilizações antigas, vitrais de igrejas medievas e até mesmo a confecção e distribuição de livros permitiram que o "contar histórias" passasse por inúmeras transformações durante a história da humanidade (RAMOS, 2009; MCCLOUD, 1995; VERGUEIRO, 2017).

Tal registro imagético, por sua vez, ora utilizado para descrever o cotidiano, ora para fins de decoração artística ou informação do público, contribuiu diretamente para que a união entre imagem e texto, mais tarde, desse origem às histórias em quadrinho, as quais podem ser descritas, através de termos semióticos, como "[...] uma forma de narrativa visual que resulta da mistura e combinação entre imagens e palavras". (ZANETTIN, 2008 , p. 12 $)^{1}$. Apesar de sua história rica, narrativas em quadrinhos foram, por muito tempo, desconsideradas na academia, "seja por elas não figurarem a literatura central e, portanto, canonizada, ou por transitarem em alguns meios acadêmicos como um gênero textual voltado apenas para jovens e adolescentes" (PIMENTEL, 2016, p. 14).

\footnotetext{
${ }^{1}$ No original: "[...] as a form of visual narrative which results from both the mixing and blending of pictures and words".
} 
Felizmente, as últimas décadas têm gerado uma grande evolução no que diz respeito à pesquisa acadêmica brasileira sobre o hipergênero quadrinho e suas especificidades de produção, utilização como recurso para a Educação, dentre outros temas (EISNER, 1985; RAMOS, 2009; VERGUEIRO, 2007, 2009; CIRNE, 1990). Esse cenário vem acompanhando, inclusive, um dos melhores momentos de produção quadrinística nacional, com obras e autores brasileiros recebendo cada vez mais destaque. Por outro lado, dentro dos Estudos da Tradução, ainda há um número relativamente escasso no que diz respeito a pesquisas científicas sobre a tradução de quadrinhos, bem como propostas metodológicas para tanto (ZANETTIN, 2008; KAINDL, 2000; CELOTTI, 2008; ASSIS, 2016).

Nesse sentido, o presente artigo procura não só enaltecer a produção quadrinística nacional, mas também contribuir para os estudos da tradução de quadrinhos por meio da análise da versão do conto Sumidouro, do romance gráfico Cumbe. A obra, escrita e ilustrada por Marcelo D'Salete, foi traduzida para a língua inglesa e publicada por uma editora de quadrinhos norte-americana, chamada Fantagraphics. Dessa maneira, com base na relação entre texto e imagem, destacaremos quais foram as saídas encontradas pela tradutora norte-americana no que diz respeito à tradução da obra.

\section{SOBRE A TRADUÇÃO DE QUADRINHOS}

Com surgimento no final do século XIX, nos Estados Unidos, através do desenvolvimento das grandes mídias, os quadrinhos perpassaram um extenso percurso histórico até adquirirem as características e formatos que conhecemos atualmente. Conforme explica Zanettin (2008), em sua obra Comics in Translation, a história das HQs está intimamente ligada à emergência das grandes mídias, principalmente no que diz respeito às suas mais variadas formas de reprodução de notícias e aumento no número de leitores.

A princípio, os quadrinhos começaram a ser impressos em edições dominicais de grandes jornais norte-americanos, em formato de tirinhas, as quais, pelo caráter cômico das narrativas, eram chamadas de Sunday funnies. Havia, portanto, uma tiragem semanal, por meio da qual os leitores precisavam esperar as próximas edições dos jornais para descobrirem o destino das personagens. Com o avanço das tecnologias de impressão e o sucesso dos quadrinhos, estes passaram a ser publicados mais periodicamente, o que promoveu a exploração de narrativas mais longas em formato de revista e livro (CHINEN; VERGUEIRO; RAMOS, 2014, p. 14). 
Com seu subsequente sucesso entre o público norte-americano, suas tradições e especificidades foram levadas a outros cantos do mundo, principalmente na Europa, onde já se haviam narrativas de "arte sequencial" consolidadas (EISNER, 1985). Assim, o aumento do consumo de leitura e o surgimento de histórias cujos temas eram do agrado do leitor contribuíram para a evolução da história mundial dos quadrinhos, a qual seguiu “[...] diferentes tradições culturais, mas frequentemente trazendo marcas da tradução". $(2008, \text { p. } 1)^{2}$.

Atualmente, quando pensamos em obras de histórias em quadrinhos que conhecemos e gostamos, cuja origem parte de um país e cultura que nos são distintos, é importante lembrar que o que lemos é resultado de um processo de tradução, a qual leva em consideração não só elementos do próprio hipergênero, mas também abrange aspectos editoriais e escolhas tradutórias.

Ao pensarmos na estrutura e temas dessas histórias de arte sequencial, alguns elementos nos são recorrentes, tais como os balões de fala, os desenhos com diferentes tipos de cores e traços, as narrativas de super-heróis (em especial da Marvel e DC Comics), os gibis da turma da Mônica ou até mesmo os mangás japoneses. No entanto, a união desses elementos, em especial da palavra e imagem, é bastante complexa e muito bem pensada e esquematizada, tanto durante a criação e edição dos quadrinhos, tanto no seu subsequente processo de tradução para outras línguas e culturas.

Conforme Zanettin (2008), os quadrinhos têm um relacionamento muito próximo a outras artes, como o cinema, as artes plásticas, a ilustração e até mesmo o design gráfico. Elementos como os balões, narrações em legendas, imagens associadas a palavras, onomatopeias, metáforas visuais e traços que dão movimento incorporam os quadrinhos, fazendo com que a simbiose entre o código escrito e imagético seja característica a essas histórias. Como diz o autor, “[...] as palavras possuem substância gráfica, formas, cores ou layouts que fazem parte da imagem". (p. 14)

De maneira simples, a linguagem dos quadrinhos consiste na justaposição entre o signo verbal e o visual. No entanto, em um nível mais complexo, tal relação contígua compõe a narrativa das HQs em seus mais variados formatos. De acordo com Celotti, “[...] a mensagem visual é composta de uma variedade de elementos, cada qual transmitindo

\footnotetext{
${ }^{2}$ No original: "[...] the history of comics in the world has evolved within different cultural traditions, but often bearing the mark of translation".

${ }^{3}$ No original: "[...] words have graphic substance, forms, colours or layouts which make them part of the picture".
} 
um significado e emprestando ritmo à narrativa: layout, tamanho e formato dos requadros, tiras e páginas, balões e calhas, cores, fonte, entre outros". (2008, p. 37)4. Portanto, é a junção de tais elementos, aliados à mensagem verbal, que compõe a essência da narrativa visual quadrinística.

Nesse sentido, imagens icônicas, tais quais podem ser observadas em um quadrinho, são imagens sígnicas, que representam uma determinada visão de mundo e exprimem um determinado significado. Tal representação de mundo, por sua vez, desempenha um papel essencial no que diz respeito à tradução de tais narrativas.

É comum pensar na imagem do tradutor como alguém que interpreta e descodifica mensagens verbais de uma língua para outra. Porém, no caso do tradutor de quadrinhos faz-se necessário haver um conhecimento que vá além daquele centrado nos pares linguísticos, mas também um que inclua um estudo e análise interpretativos de imagens e como estas se inter-relacionam com o texto escrito no decorrer da narrativa.

Por outro lado, é impossível afirmar que existe apenas uma linguagem de quadrinhos, assim como que há uma maneira única de traduzi-los. Afinal, cada país e cada cultura desenvolveram historicamente suas próprias tradições editoriais e temáticas de preferência, bem como cada imagem contida nas histórias é passível de diferentes interpretações por parte de quem as lê. Imagens são, acima de tudo, recursos para o tradutor, e não devem ser vistas como restrições, muito menos como dotadas de uma linguagem visual universal, desprovida de sentido e identidade cultural.

Como não podemos isolar as línguas de suas respectivas culturas e demais contextos, consequentemente podemos assumir que figuras, símbolos, cores e outros elementos gráficos podem ter sentidos diferentes de acordo com determinada cultura. Portanto, para lidar com cada um desses elementos,

(...) o tradutor, além de conhecer o código linguístico, deve conhecer o que está acolá desse código, tais como os aspectos sociais, políticos e culturais da cultura de chegada, bem como aspectos da sua própria cultura. Os quadrinhos, quando traduzidos, devem ser adaptados extralinguística e linguisticamente para irem de encontro às expectativas do público-alvo" (CAMILOTTI, 2012, p. 98).

\footnotetext{
${ }^{4}$ No original: "[...] the visual message is composed of a variety of elements, each of which conveys meaning and lends rhythm to the narration: layout, size and shape of panels, strips and pages, balloons and gutters, colours, lettering, etc."
} 
Nesse contexto, o tradutor, munido de uma bagagem linguístico-imagéticacultural que possibilita a leitura de quadrinhos como todo, inicia o processo tradutório de narrativas sequenciais partindo da relação justaposta entre texto e imagem. De que maneira os elementos de requadros, balões e traços dão ritmo à narrativa? Como tais interpretações influenciam escolhas de linguagem? Como isso pode ser passado para outra língua e cultura? Todas essas questões devem ser consideradas antes e durante o processo da tradução.

É interessante salientar, também, que caso o tradutor decida executar quaisquer modificações gráficas, como mudanças na imagem ou alterações tipográficas, por exemplo, estas deverão ser aprovadas pelas editoras responsáveis pelo projeto. Nesse sentido, nem sempre tais sugestões de mudança são acatadas, uma vez que envolvem custos que as casas editoriais podem não estar dispostas a arcar. Todavia, sem dúvida um agente do processo de tradução que desempenha um papel tão importante quanto o tradutor é o letrista, responsável por manter a mancha gráfica e preocupar-se com questões tipográficas e como reproduzi-las na tradução. De maneira prática, essa é a pessoa responsável por transferir o material traduzido à página da $\mathrm{HQ}$, finalizando o processo de tradução (ASSIS, 2016, p. 34-35).

Vejamos, então, como o conto Sumidouro, do quadrinho brasileiro Cumbe, foi traduzido para o inglês, e de que maneira os elementos gráficos da narrativa influenciaram diferentes leituras e interpretações, bem como resultaram em mudanças de ordem linguística e tipográfica.

\section{TRADUÇÃO DE SUMIDOURO}

O quadrinho Cumbe, lançado, primeiramente, em agosto de 2014 e depois reeditado em janeiro de 2018 pela editora Veneta, é dividido em quatro contos cuja história é contada através da perspectiva de negros escravizados de origem Banto durante o Ciclo do Açúcar no Brasil. Tais contos, intitulados Calunga, Sumidouro, Cumbe e Malungo são revelados através de ilustrações em preto e branco que, ao longo de 157 páginas, apresentam uma tentativa artística e literária para reconhecer as injustiças e dificuldades do passado escravocrata e reproduzir esse cenário colocando tais vítimas em posições de heróis da resistência.

Seu autor, Marcelo D’Salete, é graduado em Artes Plásticas e mestre em História da Arte pela USP, além de ser professor, ilustrador e autor de histórias em quadrinhos. Atualmente, sua obra mais conhecida é Cumbe, mas também escreveu e desenhou títulos 
interessantes, dentre os quais destaco Angola Janga (2017) e Encruzilhada (2016).

Cumbe, como mencionado acima, possui duas edições brasileiras. A primeira, de 2014, é mais simples e conta apenas com a própria história e um glossário ao final do livro. Em decorrência do sucesso e boa recepção da obra ${ }^{5}$, no entanto, foi produzida uma segunda edição, mais completa e que será utilizada neste texto.

O conto escolhido para análise neste capítulo intitula-se Sumidouro. Segundo o glossário presente no final do romance gráfico, sumidouro representa "um poço fundo que acreditava-se ter ligação subterrânea com um rio”. (D’SALETE, 2018). Ainda, para Clovis Moura, "era assim chamado o lugar onde se dava sumiço aos escravos rebeldes, que mereciam por isso a pena de morte". (2004 apud D'SALETE, 2018). O tema da morte, inclusive, marca presença no primeiro requadro da narrativa, conforme podemos ver na imagem abaixo.

\section{Imagem 1: imagem de abertura de Sumidouro}

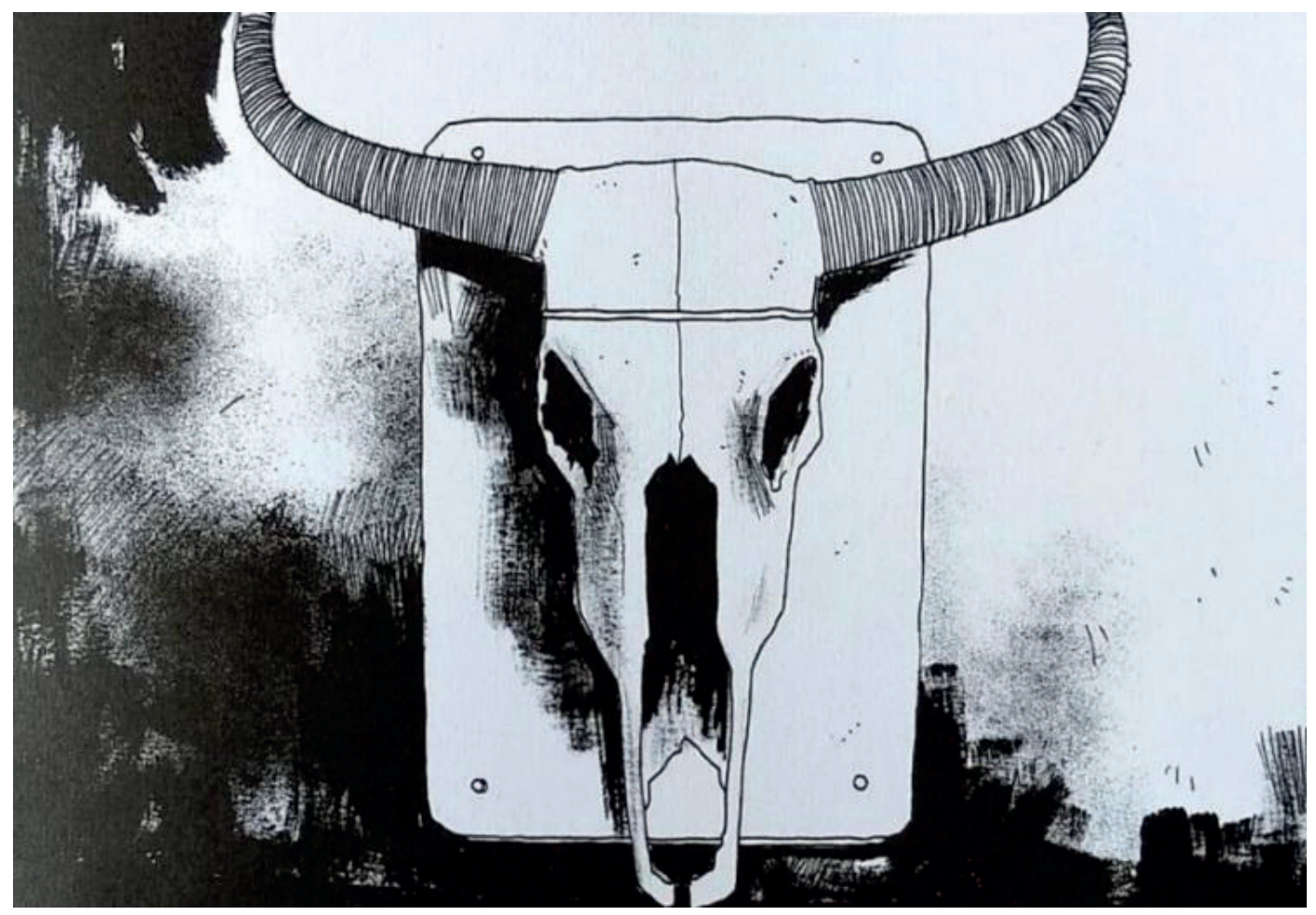

Fonte: D'SALETE, 2018, p. 49 
Segundo Espíndola, no livro Tradução Intersemiótica, de Julio Plaza, é proposta uma tipologia de traduções, as quais se dividem em primeiridade, secundidade e terceiridade. Tais divisões vão ao encontro com as categorias da Fenomenologia proposta por Peirce e, na visão do autor, transmitem a ideia de "o que muda é a maneira com que o sujeito apreende tal signo, a partir de um determinado ponto de referência". (ESPÍNDOLA, 2016, p. 1).

No que se refere, então, à imagem acima exposta, podemos apreender a seguinte interpretação, a qual norteará a leitura do conto: i) em primeira instância, ao observarmos a imagem, somos tomados por uma sensação ruim, de mau agouro. Essa primeira sensação a que entramos em contato ilustra a primeiridade, à qual se configura como um momento de ideias pré-reflexivas, como quando sentimos e experienciamos sensações após entrar em contato com determinado signo; ii) em seguida, passamos a observar alguns detalhes da imagem, a ideia do outro ali exposta. A partir disso, percebemos os traços finos do desenho, os quais, aliados a pinceladas fortes em preto contrastam com o branco, reforçando aquela sensação supracitada, a de temor e mau agouro; iii) por fim, na instância da terceiridade, concebemos o signo - no caso, a imagem no quadrinho - de maneira mais reflexiva e lógica, fazendo uso das etapas anteriores a fim de extrairmos uma interpretação da imagem. O que chama a atenção, nesse momento, diz respeito ao próprio animal fixado na parede. É comum, após a caça, empalhar animais através do processo de taxidermia e colocá-los de maneira grandiosa nas paredes. No entanto, tal procedimento é utilizado para preservar a pele dos animais, de modo que eles se assemelhem ao máximo à maneira como eram em vida. No quadrinho, a imagem de abertura do conto mostra a ossatura de um animal, a qual, aliada às cores em preto e branco, bem como ao título da história em questão, reforçam a ideia de que a narrativa não será feliz, mas sim uma representação da morte, triste e sem esperanças.

Dá-se, então, prosseguimento ao enredo. O conto narra a história de Calu, uma negra escravizada que, logo no início, agachada ao lado de um poço, diz que vai contar sua história ao senhor Tomé, dono do engenho onde trabalha.

É interessante como, nos quadrinhos, a justaposição entre texto e imagem funciona de uma maneira bastante particular no que diz respeito à composição de personagens. Raramente, há um registro escrito e verbal no que diz respeito à maneira como um personagem se veste ou se porta, uma vez que tais elementos são compartilhados com o leitor visualmente; por outro lado, no que se refere a aspectos psíquicos dos personagens das histórias em quadrinhos, muito é transmitido, também, através do elemento pictórico. 
Exemplos disso são quadros em que o posicionamento do personagem é em primeiro plano, com desenhos em que os rostos e emoções são apreendidos facilmente.

Assim, de acordo com Costa, "no plano das imagens, os recursos expressivos utilizados para singularizar um personagem - posições, gestos, fisionomias, vestimentas, etc. - contribuem para delimitar e/ou reforçar um conceito sobre ele". (2013, p. 207). Tal afirmativa pode ser percebida em Sumidouro na construção dos personagens, principalmente no que diz respeito ao relacionamento entre Calu e o senhor Tomé. A primeira é sempre ilustrada com roupas de ama, exercendo trabalhos domésticos e com a cabeça sempre baixa. Os olhos geralmente se encontram fechados ou muito baixos, representados por apenas um traço no desenho do autor. Além disso, em pelo menos oito requadros a personagem aparece chorando - com uma lágrima escorrendo em um dos olhos - ou desenhada em primeiro plano com as feições contorcidas em uma sensação que pode ser descrita como desespero.

Por outro lado, senhor Tomé é representado como um senhor de idade, com as feições duras e olhos sem emoção, que correspondem com suas atitudes no decorrer da história. Ainda, geralmente se encontra com alguma arma nas mãos - como uma corda e demonstra atitudes violentas, tais como espancamento, abuso sexual, estrangulamento, dentre outras. Tem-se, portanto, um personagem cuja construção imagética reforça a ideia de alguém perigoso, sem escrúpulos.

A sequência de requadros exposta a seguir, a qual não possui balões de fala ou qualquer outro tipo de registro verbal, é um bom exemplo de construção dos personagens, a qual, sem dúvidas, direciona e influencia a experiência de leitores no que diz respeito à interpretação da obra, assim como as futuras escolhas linguísticas por parte do tradutor. 


\section{REVISTA $\boldsymbol{X}$}

Universidade Federal do Paraná

Departamento de Letras Estrangeiras Modernas

ISSN: 1980-0614

Imagem 2: Relação entre Calu e senhor Tomé
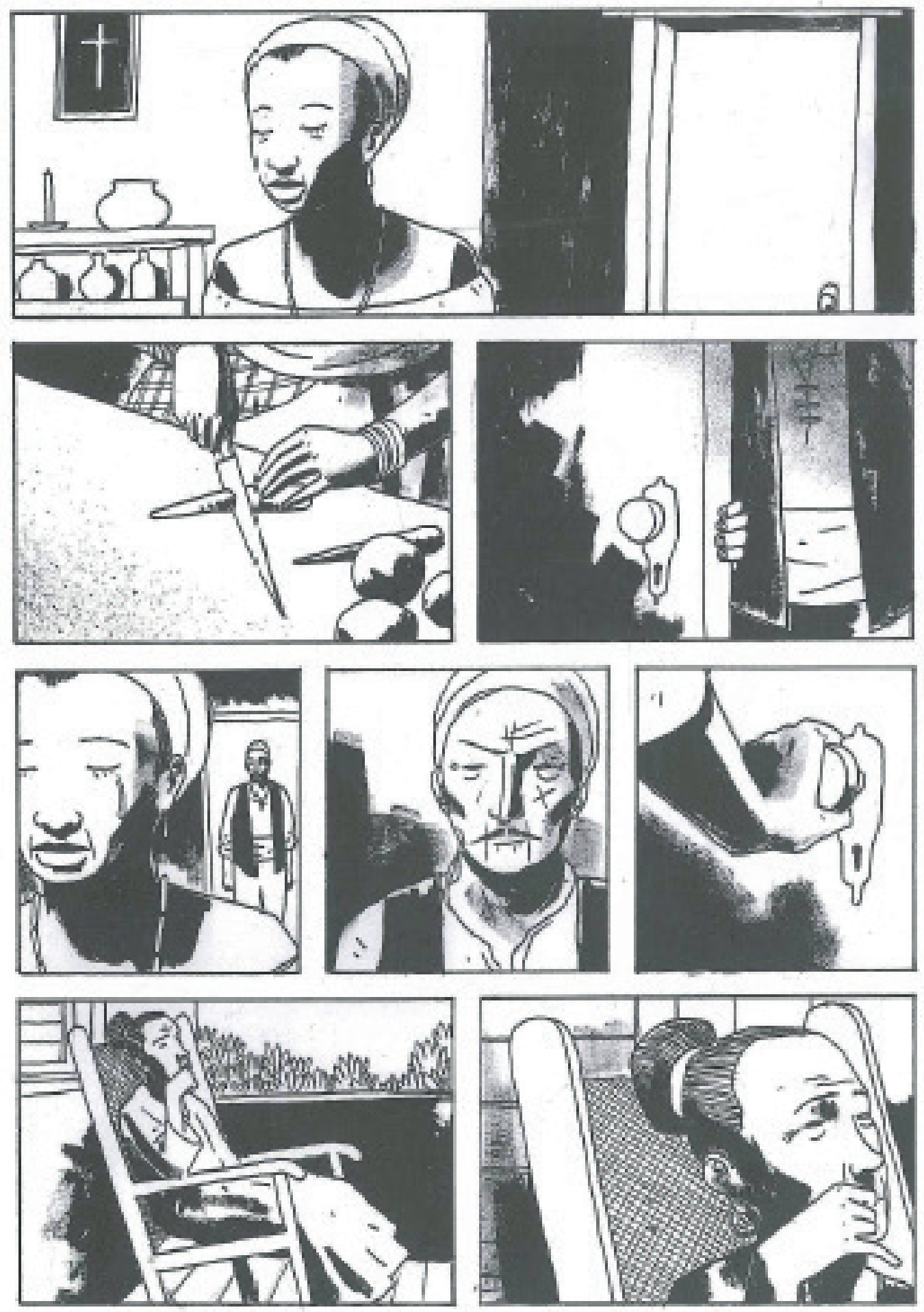

Fonte: D'SALETE, 2018, p. 56 
A falta de registro verbal nessas cenas é, no mínimo, interessante, uma vez que "a gama de empregos e possibilidades de uso do silêncio faz confirmar que o silêncio é algo significante na vida e no discurso". (COSTA, 2013, p. 214). O silêncio é, portanto, linguagem. Assim, a sequência de requadros em que Calu está trabalhando na cozinha, o senhor Tomé abre a porta, Calu chora e a porta é novamente fechada cria uma espécie de sequência cinematográfica na mente do leitor. É quase como se fosse possível ouvir as cortadas da cenoura com a faca, a porta rangendo ao ser aberta, os passos pesados do senhor Tomé ao adentrar a cozinha, o choro silencioso de Calu ao saber o que vai acontecer e, em seguida, a porta novamente se fechando com um estalo. É de responsabilidade do leitor imaginar o que acontece no momento em que essa porta é fechada e o silêncio, portanto, confere uma gama de diferentes interpretações; afinal, “[...] cada leitor pode atribuir às marcas do silêncio sentidos diversos, de acordo com seu repertório pessoal de possibilidades". (2013, p. 215).

O resultado de tal visita à cozinha tem seu resultado revelado na página seguinte: Calu está grávida. Além disso, ciente do que seu marido fizera, a esposa do dono do engenho, cujo nome não é revelado durante a história, conta para senhor Tomé de que Calu esperava um filho, o qual responde com uma risada. Nos requadros seguintes, então, dá-se as cenas do nascimento do bebê, bem como sua relação com a mãe. E é neste momento que, na versão traduzida para o inglês, algo interessante ocorre.

$\mathrm{Na}$ versão original em português de Cumbe, há uma sequência de oito requadros em que Calu está dando um banho de rio em seu filho enquanto canta um vissungo. Por vissungo, segundo o glossário presente no livro, entendemos "um canto de trabalho em versos metafóricos [...] muito usado pelos negros de Minas Gerais para se comunicarem sem serem compreendidos pelos brancos". (D’SALETE, 2018). Assim, o registro verbal presente nesses requadros lê-se: “Ei, oia lá/ Ô minino mané no Uandá... Ô mané piquinino no uandá". Tais cantigas, por se figurarem dentro da cultura afro-brasileira, não deixam de ser conhecidas pelos leitores, que leem tais passagens como uma sequência musical. No entanto, o mesmo não ocorre para um leitor estrangeiro, que desconhece tais marcas culturais. 


\section{REVISTA $\mathbf{X}$}

Universidade Federal do Paraná

Departamento de Letras Estrangeiras Modernas

ISSN: $1980-0614$

Imagem 3: Tradução do Vissungo
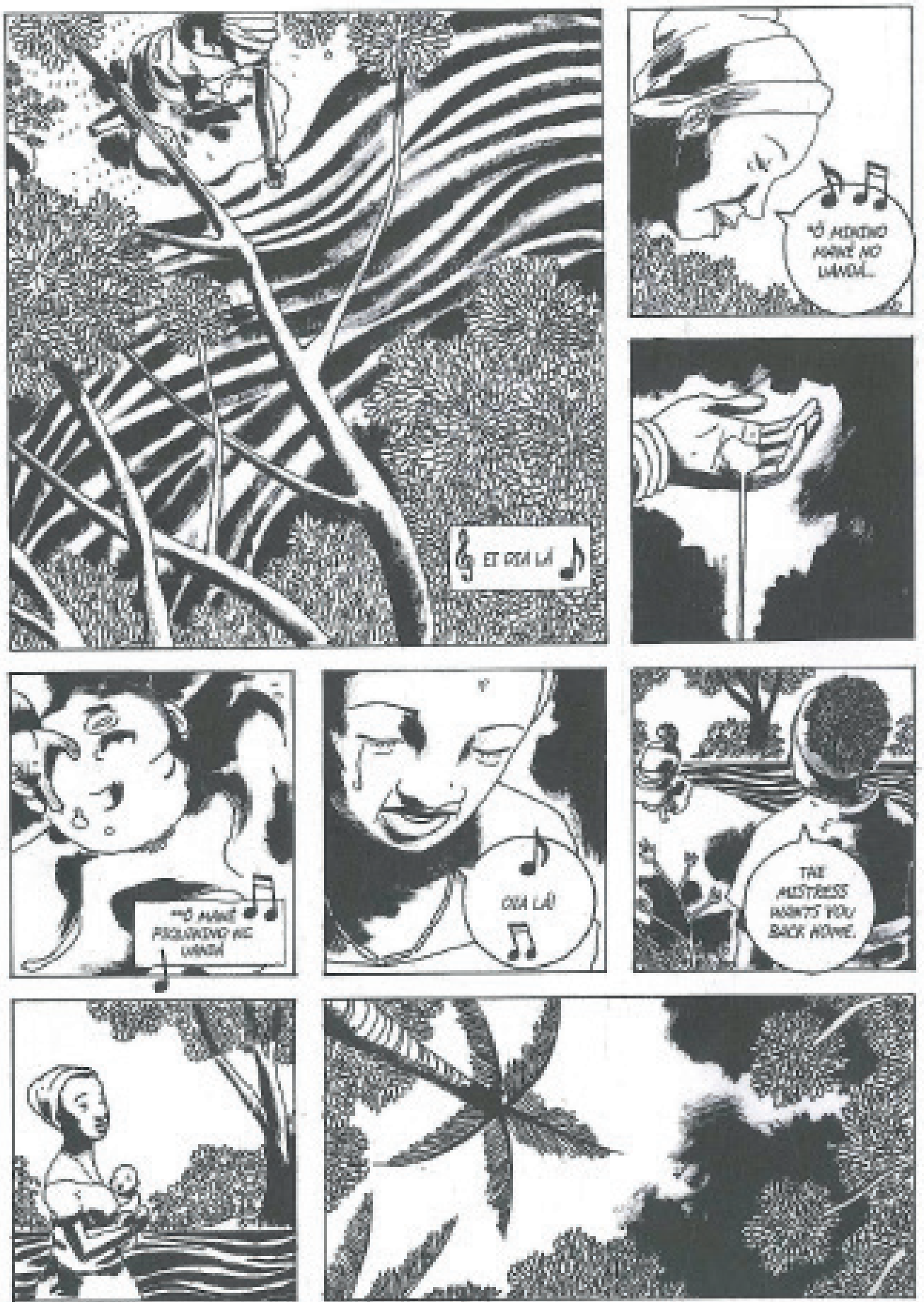

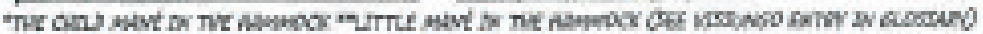

Fonte: D'SALETE, 2017, p. 62 
Como ilustra a imagem, na versão traduzida para a língua inglesa, o conto Sumidouro - cujo título em português foi mantido durante a tradução - especificamente na cena descrita acima, teve algumas modificações imagéticas. Para que o leitor estrangeiro compreendesse que aquela passagem se tratava de uma música, foram adicionadas notas musicais nos requadros, intercaladas com os balões de fala, bem como uma nota de rodapé informando ao leitor o título da música e pedindo para que este se referisse ao glossário, pesquisando o termo vissungo.

Temos um exemplo, portanto, de como a relação entre texto e imagem influencia fortemente o processo tradutório. Tem-se o costume de pensar que, em quadrinhos, há um enfoque maior no material linguístico, com pouca ou nenhuma influência dos desenhos. Tal concepção vai de encontro com uma tradução que trata da descodificação de uma mensagem apenas entre duas línguas diferentes. Porém, é importante lembrar, conforme reforça Assis (2016, p. 23), que

a tradução de quadrinhos exige o entendimento de "texto" no sentido amplo: a soma do material linguístico e dos desenhos". E este texto quadrinístico [...] demanda abordagens do tradutor que são diferentes das utilizadas para tradução em outras mídias.

No decorrer do conto, outros exemplos de tradução cuja relação entre texto e imagem foi fator determinante e condicionante para as decisões do tradutor puderam ser observadas.

Dando prosseguimento à história, aproveitando a ida do senhor Tomé à igreja e a distração de Calu com os afazeres domésticos, a esposa de Tomé rapta o filho de Calu e rapidamente se dirige ao sumidouro, onde, em uma cena dolorosa composta de cinco requadros, joga a criança poço abaixo. Quando Calu percebe que a cesta onde seu filho descansava se encontra vazia, corre até o senhor Tomé, que já havia voltado da igreja, e conta que o bebê havia sumido. De maneira, então, assombrosa, a esposa do senhor Tomé confessa indiretamente o crime, ao afirmar que "o sumidouro é fundo... bem fundo...”.

Desesperada, Calu corre até a igreja, onde bate na porta, mesmo já sendo tarde, até o padre responder. Este a escuta e, mais tarde, confronta senhor Tomé, não acreditando que ele e sua família fossem capazes de tal feito. Este é um momento no conto em que há algumas adaptações na mensagem verbal do texto original e traduzido, como podemos observar na imagem abaixo. 
Imagem 4: Calu pede ajuda ao padre

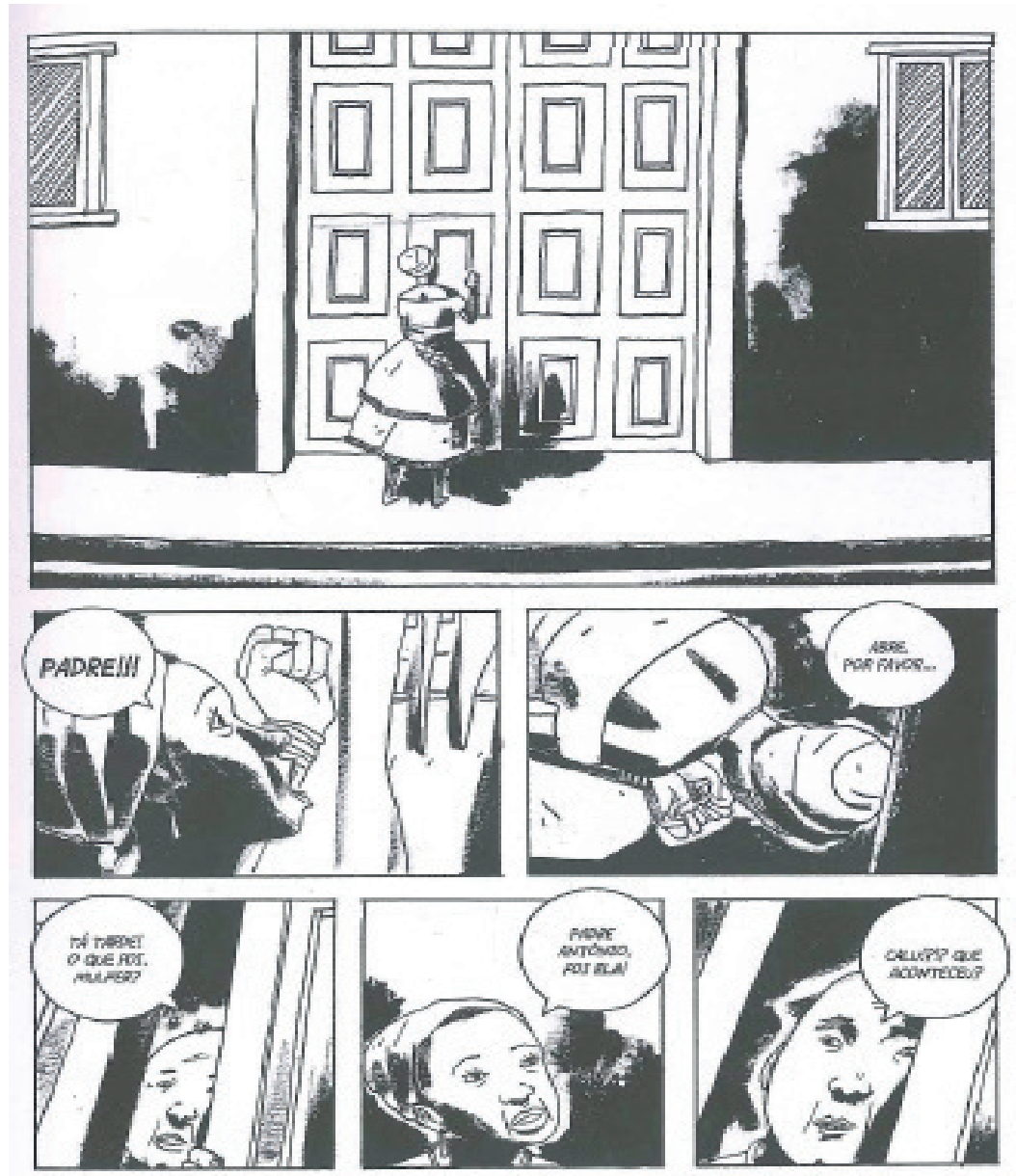

Fonte: D'SALETE, 2018, p. 69

Como podemos observar, no segundo requadro, em que Calu grita e pede ajuda ao padre, há uma imagem pequena, seguida de outras com tamanho aproximado. Essa sequência de imagens curtas dá um ritmo rápido à leitura, dando urgência ao apelo da personagem. Além disso, podemos visualizar a utilização do negrito em dois momentos: i) quando a personagem grita "PADRE!!!", com letras maiúsculas, em negrito, seguidas por três exclamações também em negrito. Nesse momento, a mensagem verbal está caracterizada de forma a representar a angústia e desespero da personagem; ii) no quinto requadro, quando a personagem informa ao padre e diz "Padre Antônio, foi ela". Há, portanto, uma ênfase no pronome feminino, de forma que o padre perceba, assim como o leitor, de que a esposa do senhor Tomé realmente havia feito algo terrível. 
Tais escolhas linguísticas, no entanto, não foram mantidas na tradução para o inglês e, apesar de serem sutis, implicaram em uma mudança tênue entre a versão original e traduzida. Vejamos, pois, como se deu tal modificação.

Imagem 5: Versão em inglês da súplica de Calu
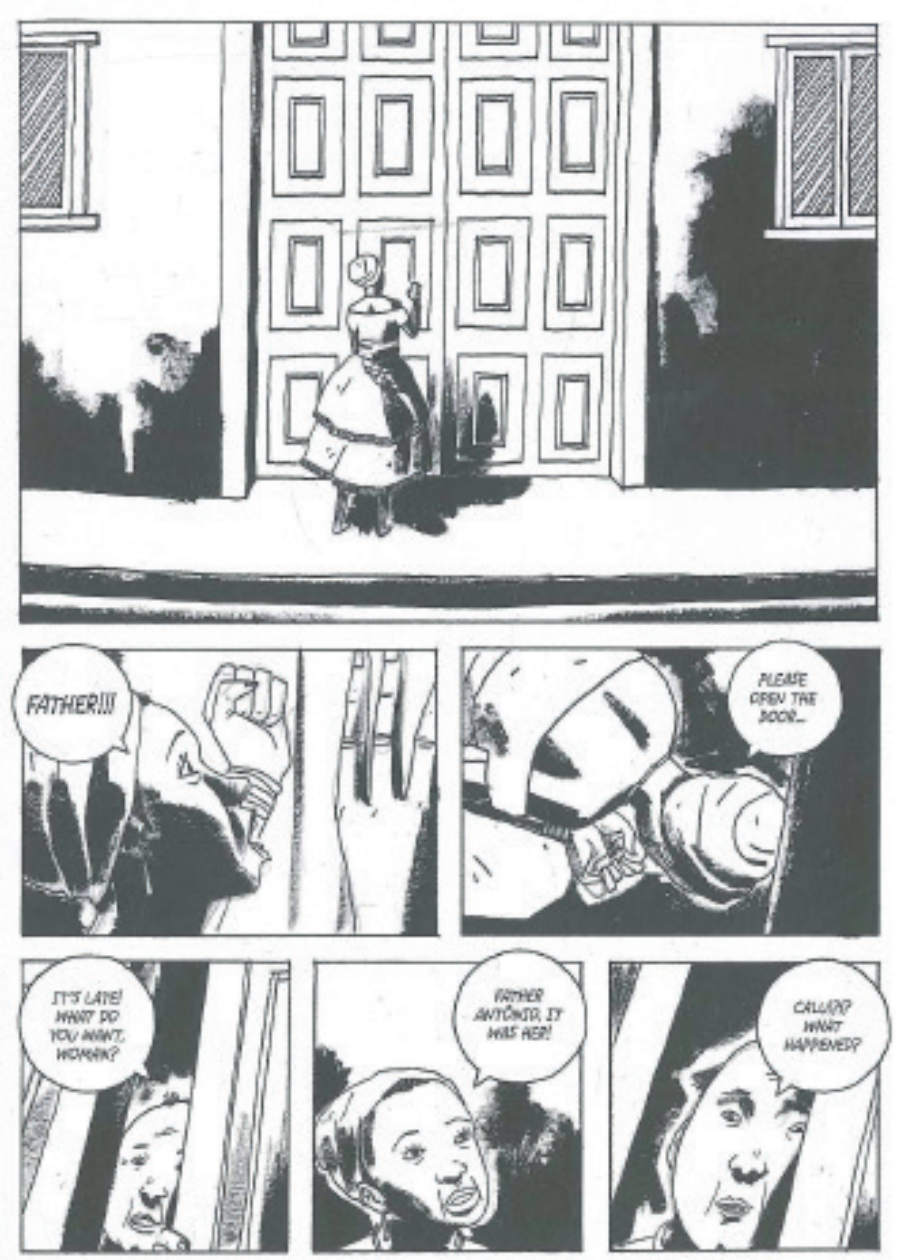

Fonte: D'SALETE, 2017, p. 71

Aqui, vemos que as palavras "Father" e "her" não foram colocadas em negrito. No primeiro caso, presente no segundo requadro, "Father" foi mantida em letras maiúsculas seguidas de três exclamações; portanto, apesar de diferente do original o efeito de urgência foi mantido; por outro lado, a não utilização do negrito na palavra "her" trouxe uma significação diferente do original, com a falta de ênfase na culpabilidade da esposa do senhor Tomé. 
No entanto, tais diferenças não comprometem o desenlace do conto. Ao descobrir que Calu havia contado para o padre, o senhor Tomé a busca na igreja, amarra suas mãos e a leva de volta para o engenho, prometendo punição. Quando tenta chicoteá-la com um pedaço de corda, Calu reage e o beija. O que vem a seguir são nove requadros pequenos, todos seguidos um do outro, sem a presença de nenhuma mensagem verbal, em que senhor Tomé corresponde ao beijo, logo em seguida tentando enforcá-la. Pensando que a havia matado, encaminha-se de volta à casa, mas Calu havia fingido sua morte $\mathrm{e}$, tentando vingar-se, retira uma zagaia ${ }^{6}$ de suas vestes, aproxima-se do pai de seu filho e levanta a arma, como podemos ver na imagem seguinte.

Imagem 6: a vingança de Calu

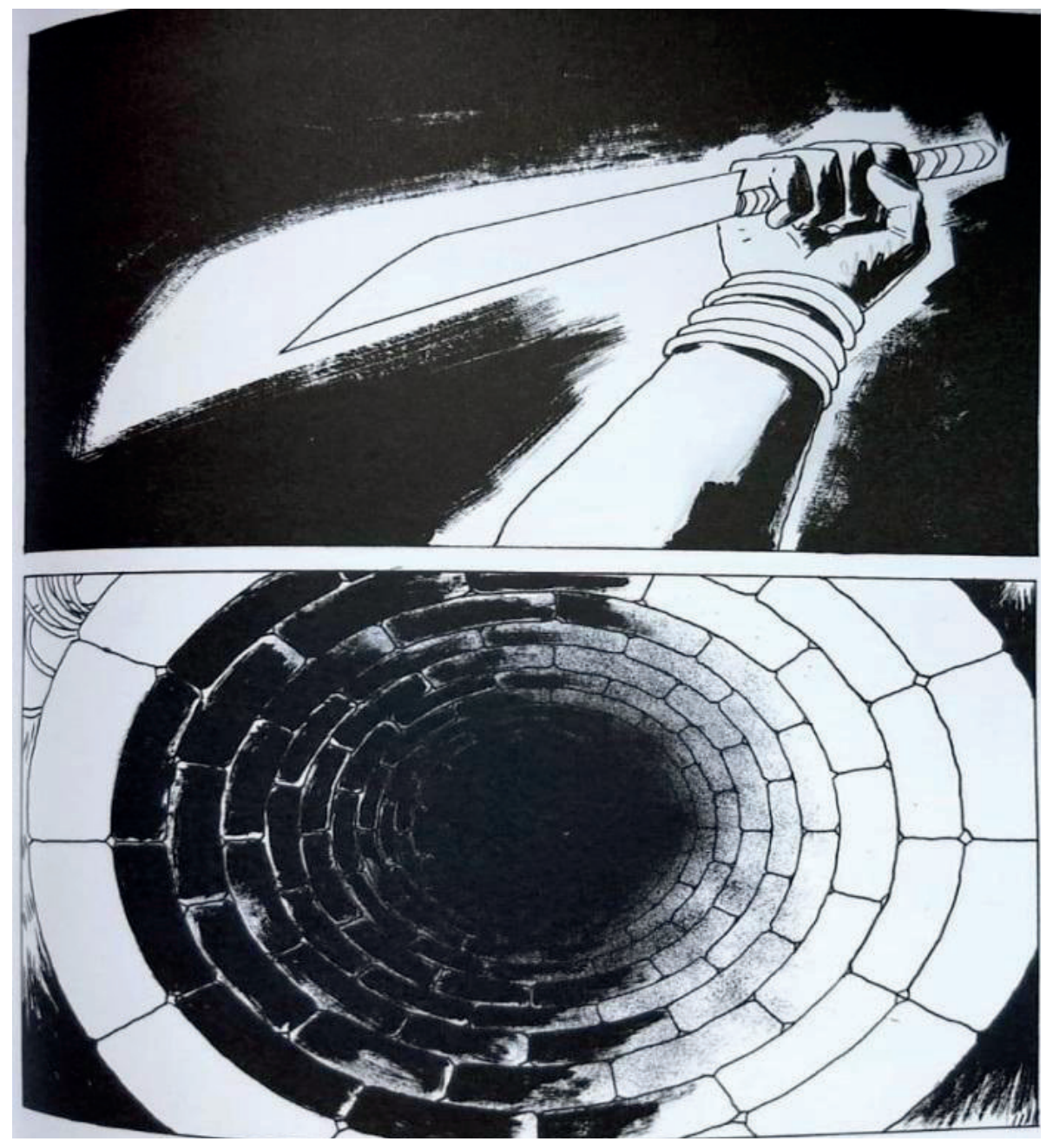

Fonte: D'SALETE, 2018, p. 81 
Neste momento, há a utilização de apenas dois requadros, grandes e, novamente, sem a presença de mensagens verbais. Cabe, portanto, ao leitor, fazer uso das cenas anteriores e imaginar o que irá acontecer. É interessante a presença dessas duas imagens, intercaladas. A primeira, com o braço de Calu levantando a zagaia em posição fatal, cumprindo sua vingança; a segunda, novamente, com a presença do sumidouro que, outras vezes durante o conto havia sido símbolo da morte. Nas páginas seguintes, constata-se que Calu realmente conseguiu matar senhor Tomé e, pensando no filho, vê-lo tornar-se estrela numa sequência de imagens que dá um belo desfecho para a história.

\section{CONSIDERAÇÕES FINAIS}

Segundo Borodo, o relacionamento harmônico entre texto e imagem em uma obra de HQ possui três dimensões. A primeira implica um processo de elaboração entre ambas as partes, através da qual a mensagem verbal meramente comunica determinados aspectos que já estão presentes no aspecto visual; a segunda dimensão refere-se a uma relação de extensão, a partir da ideia de que o texto vai além do que a imagem representa, adicionando novas informações de grande utilidade para o leitor; e a terceira, por fim, concerne uma característica de melhoria, "[...] quando o texto estende a imagem, fornecendo novas informações circunstanciais no que se refere a relações espaço-temporais"ๆ (2015, p. 23).

No conto investigado, tais dimensões de elaboração, extensão e melhoria não só se fizeram presentes, mas também tiveram influência direta na tradução para a língua inglesa, especificamente no contexto de chegada norte-americano. Isso se deu, por exemplo, nos processos interpretativos dos requadros - em que se prevaleceu, sobretudo, o silêncio e a ausência de texto escrito -, a não tradução de elementos textuais de origem Banto, as quais tiveram sua origem justificada através de elementos gráficos e, por fim, algumas modificações, ainda que sutis, nas mensagens de ordem verbal e imagética.

A análise sugere, portanto, à luz do que afirma Celotti (2008), que o tradutor de histórias em quadrinhos precisa ser, acima de tudo, um "investigador semiótico", capaz de compreender texto e imagens em uma posição justaposta e traduzir não só línguas e suas respectivas culturas, mas também suas inter-relações com diferentes universos e culturas imagéticas.

\footnotetext{
${ }^{7}$ No original: "[...] when text expands on the image, providing additional circumstantial information concerning spatial or temporal relations".
} 


\section{REFERÊNCIAS:}

ASSIS, E. Especificidades da tradução de histórias em quadrinhos: abordagem inicial. TradTerm, v.27, p. 15-37, 2016.

BORODO, M. Multimodality, translation and comics. Perspectives: Studies in Translatology. v. 23, n. 1, p. 22-41, 2015.

CAMILOTTI; LIBERATTI. Desvendando os segredos da tradução de quadrinhos: uma análise da tradução de Romeu e Julieta, da Turma da Mônica. Belas Infieis, v. 1, n. 1, p. 95-112, 2012.

CELOTTI, N. The Translator of Comics as a Semiotic Investigator. In: ZANETTIN, F. Comics in Translation. New York: Routledge, 2008.

CIRNE, M. História e Crítica dos Quadrinhos Brasileiros. Rio de Janeiro: Ed. Europa, FUNARTE, 1990.

COSTA, L. Machado em quadrinhos: aspectos discursivos de uma tradução intersemiótica. Scientia Traductionis, n. 14, p. 198-220, 2013.

CHINEN, N.; VERGUEIRO, W.; RAMOS, P. Literatura em Quadrinhos no Brasil: uma área em expansão. In: RAMOS, P.; VERGUEIRA, W.; FIGUEIRA, D. Quadrinhos e Literatura: diálogos possíveis. São Paulo: Criativo, 2014.

D’SALETE, M. Cumbe. 2 ed. São Paulo: Veneta, 2018.

D’SALETE, M. Encruzilhada. São Paulo: Veneta, 2016.

D’SAlETE, M. Angola Janga: uma história de Palmares. São Paulo: Veneta, 2017.

D'SALETE, M. Run for it: stories of slaves who fought for their freedom. Trad. Andrea Rosenberg. Seattle: Fantagraphics, 2017.

EISNER, W. Comics \& Sequential Art. Tamarac: Poorhouse Press, 1985.

ESPÍNDOLA, B. Tradução, transcriação e intertextualidade: a semiose intermídia. In: XI Congresso Internacional da Abralic, 2008, São Paulo. Anais eletrônicos. São Paulo: USP, 2008. Disponível em: <http://www.abralic.org.br/eventos/cong2008/AnaisOnline/ simposios/pdf/061/BERNARDO_ESPINDOLA.pdf>. Acesso em: 16 set. 2018. 
KAINDL, K. Thump, Whizz, Poom: A Framework for the Study of Comics under Translation. Target, v. 11, p. 2, 2000.

MCCLOUD, S. Desvendando os quadrinhos. Trad. Hélcio de Carvalho e Marisa do Nascimento Paro. São Paulo: Makron Books, 1995.

PIMENTEL, A. C. A. S. O habitus dos tradutores de Histórias em Quadrinhos de super-heróis da Marvel e DC Comis no Brasil. 2016. 244f. Dissertação de Mestrado Universidade de São Paulo, São Paulo, 2016.

RAMOS, P. Quadrinhos: gênero ou hipergênero? Estudos Linguísticos, v.38, n.3, p.355$367,2009$.

RAMOS, P. A leitura dos quadrinhos. São Paulo: Contexto, 2009.

VERGUEIRO, W. A atualidade das histórias em quadrinhos no Brasil: a busca de um novo público. História, Imagem e Narrativas, n.5, p. 1-20, 2007.

VERGUEIRO, W. Brazilian Comics: Origin, Development and Future Trends. In: L'HOESTE, H; POBLETE, J. Redrawing the Nation: National Identity in Latin/o American Comics. New York: Palgrave Macmillan, 2009.

VERGUEIRO, W. Pesquisa acadêmica em histórias em quadrinho. São Paulo: Criativo, 2017.

ZANETTIN, F. Comics in Translation. New York: Routledge, 2008. 